http://jmscr.igmpublication.org/home/ ISSN (e)-2347-176x ISSN (p) 2455-0450

crossref DOI: https://dx.doi.org/10.18535/jmscr/v7i12.50

Journal Of Medical Science And Clinical Research

\title{
Pprom - Its Prevalence, Predictors, maternal and neonatal outcomes
}

\author{
Authors \\ Dr Fariha Aman ${ }^{1 *}$, Dr Samar Mukhtiar ${ }^{2}$, Dr Munaza Aman ${ }^{3}$ \\ ${ }^{1}$ Medical officer (Incharge Family Planning Clinic) \\ ${ }^{2}$ Medical Officer, LD Hospital Srinagar Kashmir \\ ${ }^{3}$ Medical Officer J\&K Health Department \\ Department of Obstetrics \& Gynecology, Lal Ded Hospital \\ (An associated Hospital of Government Medical College, Srinagar) \\ *Corresponding Author \\ Dr Fariha Aman
}

\begin{abstract}
Background: Preterm birth is leading cause of perinatal mortality and morbidity worldwide and account for $75 \%$ of neonatal deaths. pprom accounts for $30 \%$ of preterm births in world. A prospective study was carried out in kashmirs lalla ded hospital, (which is Valleys biggest tertiary care maternity hospital) With aim to study prevalence of preterm premature rupture of membranes \& to identify those women who are at its increased risk \& fetal and maternal outcome. Predictors of pprom by patient demographics can improve diagnosis, allow early intervention and hence a reduction in health and economic burden.

Method: A total of 2116 patients were admitted in labour room of Lal Ded hospital from march 2019 to September 2019.out of these patients 382 patients were confirmed to have PPROM. a detailed history was taken, and gestational age confirmed, general, systemic and obstetric examinations were done. all baseline investigations were carried out along with obstetric ultrasound. every patient was followed till her delivery, and the mode of delivery and maternal and fetal outcomes were recorded and data was analysed statically.

Result: In our study prevalence of PPROM was $18 \%$. More common in young age group of 20 to 25 years (56.8\%),patient belonging to low socioeconomic status(48.2\%), those who were unbooked antenatal cases (52\%) \& Primigravidas (47.8\%). Risk of PPROM was highest in patients who had history of recurrent bacterial vaginosis in their antenatal period.(42\%),recurrent bacteriuria (31\%), only (24.6\%) patients had history of previous pre term deliveries.

In present study $62 \%$ cases had normal vaginal delivery, $10 \%$ had instrumental delivery and about $28 \%$ had LSCS.Fetal distress was most common indication for LSCS followed by non progression of labor.

Postnatally $18 \%$ mothers \& $26.8 \%$ babies developed infection and needed antibiotics. Majority of babies born were low birth weight babies (72.3\%). Perinatal mortality rate was $16 \%$ of total births.

Conclusion: PPROM is responsible for considerable maternal morbidity, neonatal morbidity and mortality. The demographic variables with previous antenatal history can help to predict high risk cases so as to screen and treat them beforehand to decrease the prevalence of preterm births and perinatal mortality.
\end{abstract}




\section{Introduction}

Preterm prelabour rupture of membranes (PPROM) is defined as the spontaneous rupture of fetal membranes prior to the onset of labour and before 37 weeks of gestation. It complicates $2 \%$ of pregnancies and occurs in 14000 pregnancies in UK and 15000 pregnancies in USA and accounts for $30 \%$ of preterm deliveries ${ }^{(1)}$. it is associated with significant maternal risk including chorioamnionitis with serious systemic infection and neonatal morbidity and mortality including prematurity, sepsis, pulmonary hypoplasia. ${ }^{(2)}$ preterm birth carries significant socioeconomic burden. The cost of preterm birth estimated by Khan et al was 15,688 pounds up to 34 weeks and 12,104 pounds for up to 37 weeks. ${ }^{(3)}$. It is therefore important that asymptomatic high risk women and symptomatic woman in threatened preterm labour are identified early to allow preventive interventions and management strategies, to reduce the incidence of perinatal mortality and morbidity.

\section{Materials and Methods}

The study was conducted from March 2019 to September 2019 in all patients who presented with preterm premature rupture of membranes and were admitted in labour room of LALLA DED hospital. Those patients who had medical comorbidities like PIH, pre eclampsia, eclampsia, diabetes mellitus; obstetrical complications like polyhydramnios, placental abruption, malpresentations, cephalo pelvic disproportion and fetal complications like congenital anomalies and IUGR were excluded from the study.

A detailed history of the patients under study was recorded followed by general, systemic and obstetric examination. Those patients who gave history of leaking with clear fluid on perspeculum examination along with decrease in AFI on obstetric ultrasound were considered to have PPROM. Patients who had signs of infection as depicted by fever (body temperature $>38 \mathrm{C}$ ) with one or more of the following: uterine tenderness, fetal/maternal tachycardia, foul smelling amniotic fluid draining per vaginum, in the absence of any other reason for fever were put on broad spectrum antibiotics.

All baseline investigations along with obstetric ultrasound were done.

All these patients were observed for the mode of delivery, APGAR score of the baby, and postnatal maternal and neonatal outcomes.

\section{Results}

A total of 2116 patients were admitted during this study period, out of which 382 patients were confirmed as PPROM leading to the prevalence of $18 \%$.

Table 1: Demographic characters of cases in the study

\begin{tabular}{|l|c|c|}
\hline Demographic characters & number & \%age \\
\hline Age wise distribution: & & \\
\hline 20-24yrs & 217 & $56.8 \%$ \\
\hline $25-29 y r s$ & 94 & $24.6 \%$ \\
\hline 30-35yrs & 47 & $12.3 \%$ \\
\hline$>35 y r s$ & 24 & $6.2 \%$ \\
\hline Gestational age: & & \\
\hline 28wks-31wks 6days & 94 & $24.60 \%$ \\
\hline 32wks-34wks6days & 128 & $33.50 \%$ \\
\hline Upto 37weeks & 160 & $41.88 \%$ \\
\hline Parity: & & \\
\hline primi & 229 & $59.94 \%$ \\
\hline multi & 153 & $40.05 \%$ \\
\hline Antenatal checkups & 234 & \\
\hline Booked cases & 135 & $31.25 \%$ \\
\hline Unbooked cases & & \\
\hline Socioeconomic status: & 284 & $74.34 \%$ \\
\hline low & 98 & $25.65 \%$ \\
\hline high
\end{tabular}

Table 1 depicts majority of patients presenting with PPROM were young with age less than 35 years.it was more frequent in gestational age between $32 \mathrm{wks}$ to $37 \mathrm{wks}$. PPROM was more frequent among low socioeconomic class (74.34\%) compared to higher class $25.65 \%$. PPROM was more frequent among primigravidas $(59.94 \%)$

Table 2: Obstetrical History

\begin{tabular}{|l|c|c|}
\hline history & number & $\%$ \\
\hline 1.h/o bacteriuria & 48 & $12.56 \%$ \\
\hline 2.h/o bac vaginosis & 186 & $48.6 \%$ \\
\hline 3.h/o bleeding pv & 88 & $23 \%$ \\
\hline 4.h/o one two or more preterm deliveries & 62 & $16.2 \%$ \\
\hline 5h/o instrumental deliveries & 69 & $18 \%$ \\
\hline 6 h/o early pregnancy losses & 58 & $15.1 \%$ \\
\hline
\end{tabular}


Table 2 shows the relationship between associated history and PPROM.48.6\% patients had Infection of the genital tract antenatally. Recurrent urinary tract infection in the antenatal period was linked with $12.56 \%$ PPROM cases. History of first and second trimester vaginal bleeding was seen in $16.2 \%$ PPROM cases. In our study it was seen that there was very less $18 \%$ association of PPROM with h/o previous preterm deliveries also. h/o previous spontaneous or induced abortion was seen in $15.1 \%$ cases.

Table 3: Mode of delivery

\begin{tabular}{|l|c|c|}
\hline Type of delivery & number & $\%$ \\
\hline Vaginal delivery & 237 & $62 \%$ \\
\hline Instrumental delivery & 38 & $10 \%$ \\
\hline LSCS & 107 & $28 \%$ \\
\hline
\end{tabular}

Table 3 shows the labour outcome in these cases. Majority underwent vaginal delivery (62\%), while LSCS rate was $28 \%$ followed by instrumental delivery $(10 \%)$.

Table 4: Postnatal maternal and fetal outcome

\begin{tabular}{|l|c|c|}
\hline & Number & $\%$ \\
\hline Maternal infection present & 71 & $18.6 \%$ \\
\hline Fetal infection present & 132 & $34.6 \%$ \\
\hline Low birth weight & 257 & $67.3 \%$ \\
\hline Intrapartum death & 24 & $6.2 \%$ \\
\hline Neonatal death & 55 & $14.3 \%$ \\
\hline Maternal deaths & 0 & $0 \%$ \\
\hline
\end{tabular}

Table 4 shows the maternal and fetal outcomes in these patients. $18.6 \%$ mothers developed infection and required broad spectrum triple antibiotic cover.34.6\% babies needed antibiotic and NICU admission in view of sepsis. the rate of Low birth weight babies in our study was as high as $67.3 \%$. Also there was an incidence of $6.2 \%$ intrapartum deaths and $23.8 \%$ neonatal deaths which is a very high figure. However there was no maternal death noted in this study.

\section{Discussion}

THE prevalence of PPROM in this study was $18 \%$ which is much higher than reported from England $(1 \%),{ }^{(4)}$. united states $(1-2 \%)^{(5)}$, Canada2-3\%, ${ }^{(6)}$ punjab5.4\% ${ }^{(7)}$ Abbottabad $9.6 \%{ }^{(8)}$. In present study the different demographic variables were observed. The commonest age group was 20-24 years $(56.8 \%)$. which correlated well with kodkany DS et al and Devi A et al. ${ }^{(9-10)}$ although most of the studies show that risk of PPROM increases with age. In our study only (6.2\%) patients were more than 35 years of age. The incidence of PPROM was high in cases belonging to, low socioeconomic background explaining the nutritional deficiencies, less hygiene, less frequent health care visits during antenatal period which are similar to as reported in other studies ${ }^{(11-13)}$. In present study increased cases of PPROM Were observed in primigravidas than multigravidas which is again contrary to many studies in which multiparas were seen more associated to PPROM. The incidence of PPROM was also seen higher in unbooked cases compared to booked cases which is stastically similar to findings in many studies all over the world ${ }^{(14)}$. In present study association of PPROM between genitourinary infections, antepartum haemorrhage and previous history of abortion was also seen. So routine check up is highly needed to treat these infections during antenatal period. Similar findings were seen in many studies done in india. ${ }^{(15)}$

In our study only $16.2 \%$ patients had h/o previous preterm deliveries. this incidence is higher than reported by Tahir et al $14.7 \%^{(16)}$ and Charles J et al $14.7 \%^{(17)}$ but lesser than reported by $\mathrm{J}$ Ayub Coll Abbottabad ${ }^{(8)}$.

Caesarean section rates in our study were $28 \%$ which is similar to findings of Swathi pandey et $\mathrm{al}^{(18)}$ but higher than study reported from Punjab $^{(7)}$, and still lower than the study reported by Charles et $\mathrm{al}^{(17)}$ in which the incidence of caesarean section was 58.7\%.In present study caesarean section was mainly done for fetal distress followed by non progression of labour, while as in the above mentioned study caesarean section was done before labour.

In this study there were large number of low birth weight babies putting a burden on neonatal facilities. The number of low birth weight babies in this study were $67.3 \%$ which is very high as compared to Unites states and California cohorts $^{(5)}$. 
Perinatal mortality in this study was $14.2 \%(142 / 1000)$ which is lower than noted by Tahir et al but higher than reported by Multer et al $9.3 \%(19 S)$ and Charles et $\mathrm{al}^{(17)}$. Foetal deaths in our study were reported to be as high as $6.2 \%$ as against the usual incidence of $1 \%$ of patients with PPROM. In our study maternal morbidity was $18.6 \%$ and all these patients were given broad spectrum antibiotics thus reducing the risk of endometritis and chorioamnionitis.

\section{Conclusion}

PPROM is one of the important and leading cause of preterm births resulting in increased fetal morbidity and mortality. Hence it is advisable to develop the scoring system involving demographic risk factors with previous history and emphasising the routine antenatal checkups to identify high risk cases and to treat them before rupture of membranes leading to the improvement in neonatal mortality and morbidity.

\section{Conflict of Interest: None \\ Funding: None}

\section{References}

1. Mercer BM. Preterm premature rupture of membranes. obset gynecol.2003;101 (1): 178-193.

2. Douvas SG, Brewer MJ, Mckay ML, Rhodes PG, Kahlstorf JH, Morisson JC. Treatment of premature rupture of membranes. J Reprod Med.1984; 29(10):741-744.

3. Khan KS, Honest H. Risk of screening for spontaneous preterm labour. Best Pract \& Res Clin obstet \& Gynecol. 2007; 21(5):821-830.

4. Parry S, Strauss JS $3^{\text {rd }}$.premature rupture of fetal membranes. N Engl J Med 1998; 338:663-70.

5. Benitz WE, Gould JB, Druzin ML. Risk factors for early onset of streptococcal sepsis group B. Estimation of odds ratio. Critical literature review. pediatrics 1999;103(6):e77.
6. Smith G, Rafuse C, Anand N, Brennan B, Connors G, Crane J,et al. prevalence, management and outcome of women in Canada. J Obstet \& Gynecol Can 2005;27 (6):547-53.

7. Tahir S, Aleem M, Aziz R. Incidence and outcome of preterm premature rupture of membranes. Pak J Med Sci 2002;18(1):2632.

8. Noor S, Fawwad A, Shahzad H, Sultana R, Bashir R. Fetomaternal outcome in patients with premature rupture of membranes. J Ayub Med Coll Abbotabad. 2010;22(1):164-7.

9. Devi A, Rani R.Premature rupture of membranes-A clinical study. J Obstet Gynecol India.1996;46:63.

10. Kodkany, Telang, Premature rupture of membranes, a study of 100 cases. J Obstet Gynecol India 1991;41:492.

11. Chen CP, Wang KG,Yang Yc,See LC. Risk factors for preterm birth in upper middle class Chinese population. Eur. J. Obstet \& Gynecol. Repor. Biol. 1996;70(1):53-9.

12. Obed Jy, Zarma A, Mamma L. Antenatal complications in adolescent mothers aged below 14 years. Afr J Med Sci 1997;26(34):179-82.

13. Meis PJ, Michelutte R, Peter TJ, Wells HB, Sands E,Coles EC, et al. Factors associated in preterm birth in Cardiff Wales I.A univariable and multivariable analysis. Am J Obstet \& Gynecol 1989; 160:890-906.

14. El Messedi A, Cameron A. Diagnosis of premature rupture of membranes: inspiration from the past and insight for the future. J Obstet \& Gynecol Can. 2010;32:561-9.

15. Vogel JP, Lee AC, Souza JP. Maternal morbidity and preterm birth in 22 low and middle income countries: a secondary analysis of the WHO Global Survey 
dataset. BMC Pregnancy Childbirth. 2014;14:56.

16. Tahir S, Aleem M, Aziz R. Incidence and outcome of preterm premature rupture of membranes. Pak J Med Sci 2002;18(1):2632.

17. Charles PJ, Muriel R, Rene E, Oliver C, Pascal G, et al.a prospective population based study of 598 cases of PPROM between 24 and 34 weeks gestation: description, management and mortality (dominos cohort).Eur J Obstet \& Gynecol Reprod Biol 2005;121(2):164-70.

18. Swati Pandey, Dave A, Bandi S. Maternal and fetal outcomes in cases of PPROM.J Obstet \& Gynecol India.2000;51:63.

19. Ananth CV, Guise JM, Thorp JM Jr.Utility of antibiotic therapy in preterm premature rupture of membranes .A meta analysis Obstet \& Gynecol Surv 1996;51:324-8. 